Hydrology and Earth System Sciences, 9, 3-14, 2005

www.copernicus.org/EGU/hess/hess/9/3/

SRef-ID: 1607-7938/hess/2005-9-3

European Geosciences Union

\title{
Bringing it all together
}

\author{
J. C. I. Dooge \\ Centre for Water Resources Research, University College Dublin, Earlsfort Terrace, Dublin, Ireland
}

Received: 6 December 2004 - Published in Hydrology and Earth System Sciences Discussions: 7 December 2004

Revised: 6 April 2005 - Accepted: 7 April 2005 - Published: 9 May 2005

\begin{abstract}
The various elements of the hydrological cycle are discussed in outline from the point of view of making progress in analysis through appropriate simplification of these complex processes. Parallels between stochastic and deterministic analysis and between linear and non-linear conceptual models are referred to. The emphasis is on similarities and contrasts between the analysis of hydrologic processes over the range of scales from the water molecule to the global water balance.
\end{abstract}

\section{Dealing with complexity}

Science in general has moved from a reductionist approach which was characterised as a process of "knowing more and more about less and less" to a holistic or synthetic approach which attempts to breach interdisciplinary and other conceptual boundaries. Hydrology in the past has been highly reductionary particularly in the separation between the individual processes of the hydrological cycle and between deterministic and stochastic hydrology.

It is important to realise that most hydrological systems of interest represent a zone between purely deterministic approach in which equations can be analysed and a stochastic approach in which statistical distributions can be handled. The relationship in this regard is well illustrated by the characterisation of the three categories of mechanisms, systems and aggregates as shown in Fig. 1 due to Weinberg (1975). Mechanisms are characterised as organised simplicity, aggregates are characterised as unorganised complexity, and the intermediate category of systems characterised as organised complexity. In seeking to understand the behaviour of hydrologic systems of interest it is necessary to draw on standard results from both the statistical study of random systems and

Correspondence to: J. C. I. Dooge

(jdooge1@eircom.net) the deterministic analysis of classical fluid mechanics and hydraulics.

It can readily be shown that a large series of Bernouilli trials with equal probability of success and failure $(p=1 / 2$ and $q=1 / 2$ ) results in the normal distribution which is symmetrical. There is remarkably little curiosity about how this result would be modified if the probability of failure was not equal to one half. Velikanov (1962) gave a heuristic development suggesting that the answer to this problem is that in this case the normal distribution would be replaced by the gamma distribution which is skewed rather than symmetrical. One of the earliest hydrological observations must have been the tendency of surface water to flow downhill and for streams to join with one another in a network of channels leading to an outlet at a lower level. This lack of symmetry must be an important element in any stochastic approach to the problem of catchment runoff.

In approaching hydrological analysis from the direction of the simpler mechanisms of fluid mechanics and hydraulics, the most useful strategy to follow is that based on the rigorous analysis of simplified equations of motion. This approach has been well summarised by Pedlosky (1979): "One of the key features of geophysical fluid dynamics is the need to combine approximate forms of the basic fluid-dynamical equations of motion with careful and precise analysis. The approximations are necessary in order to make any progress possible, while precision in analysis is demanded to make the progress meaningful".

In what follows, an account is given of the progress that can be made in the study of hydrological systems by the application of a strategy of simplification to the basic equations.

\section{Range of scales}

A key task in hydrology is to attempt to unravel the organisation of the complexity of hydrologic processes at various

(C) 2005 Author(s). This work is licensed under a Creative Commons License. 


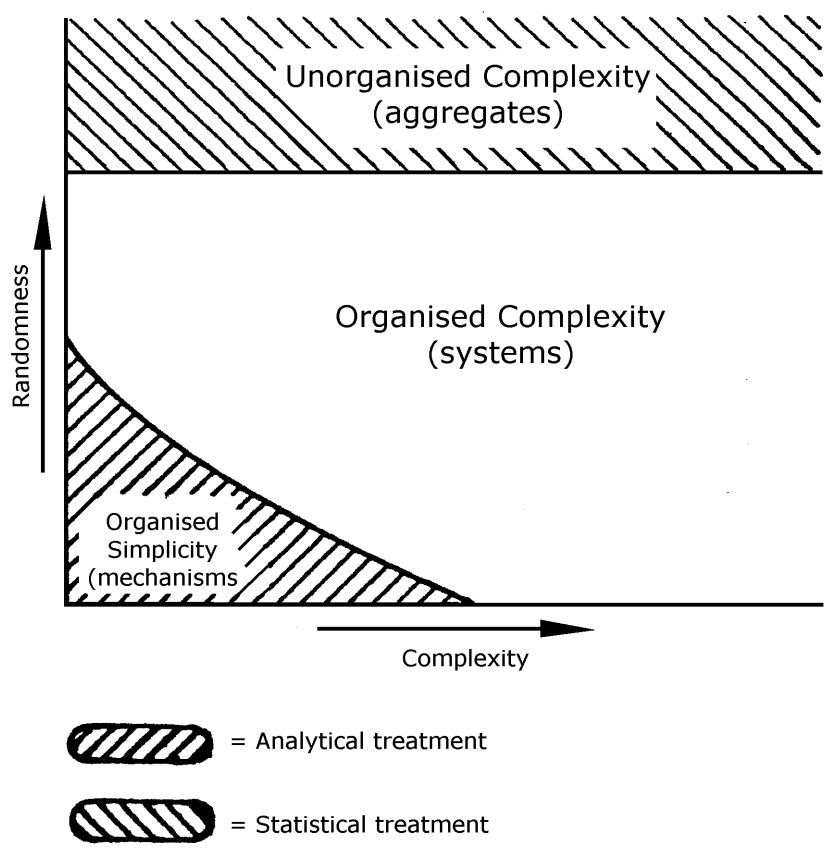

Fig. 1. Mechanisms, systems, and aggregates.

scales. In studying the occurrence and movement of water it is necessary to analyse the processes at key scales varying by over 18 orders of magnitude from the water molecule $\left(10^{-10} \mathrm{~m}\right)$ to the global planetary scale $\left(10^{8} \mathrm{~m}\right)$ as shown as a logarithmic plot in Fig. 2 (Dooge, 1992a).

One of the first facts to be explained about the occurrence of water is the abundance of liquid water at the surface of planet Earth with its mean temperature of about $15^{\circ} \mathrm{C}$. The physical properties of water $\left(\mathrm{H}_{2} \mathrm{O}\right)$ are distinctly different from those of hydrogen sulphide $\left(\mathrm{H}_{2} \mathrm{~S}\right)$ even though oxygen (O) and sulphur (S) are immediate neighbours in the sixth column of the table of chemical elements (Dooge, 1983). At $15^{\circ} \mathrm{C}$ water is an odourless liquid whereas hydrogen sulphide is a pungent gas. This phenomenon due to the dipole moment of the hydrogen bond is essentially a property of water being non-isotropic at the molecular scale $\left(10^{-10} \mathrm{~m}\right.$.). The explanation lies in the existence of the hydrogen bond in water at the molecular scale.

When we come to consider the movement of water at the continuum scale $\left(10^{-5} \mathrm{~m}\right)$, we postulate a relationship between the shear stress on a given plane and the strain on another plane. In order to handle the 4-dimensional tensor connecting these two relationships (which will in general have 81 elements), it is possible to make progress and reduce these 81 elements (reduced to 36 if we assume symmetry) to the two properties of dynamic viscosity and bulk viscosity, by the simple assumption that water at a continuum scale is isotropic (Dooge, 1983). The contrast between these two basic assumptions is a warning to hydrologists of the need to distinguish between the different simplifying assumptions

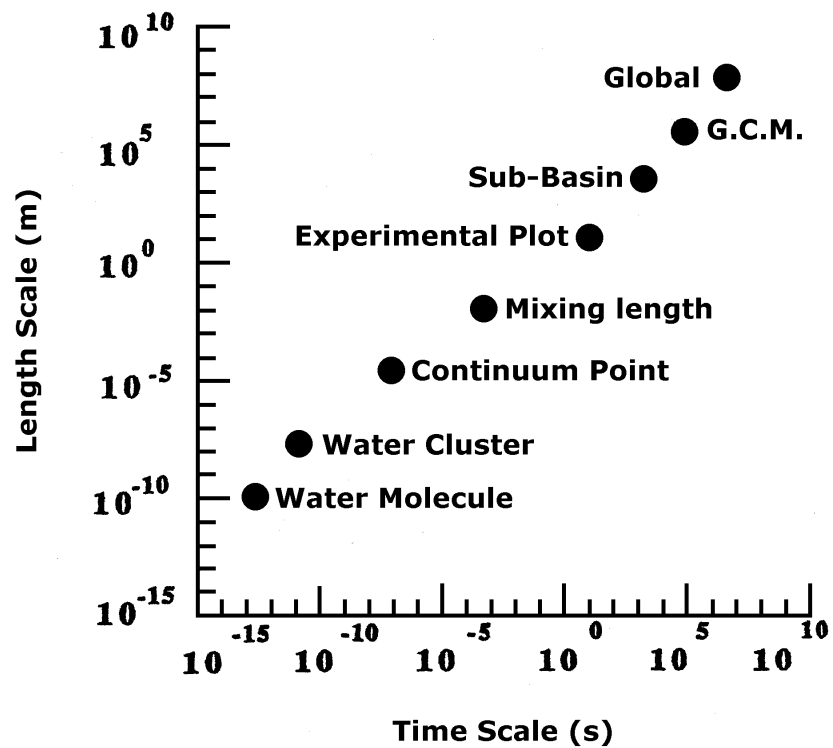

Fig. 2. Scales in hydrology.

necessary for initial progress in analysis at different hydrological scales.

Progress can be sought at any particular scale through a number of forms of simplification of the basic equations and evaluating the range of error in the simplified solution. A wide variety of forms of simplification have been used in hydrology (Dooge 1997). These include (1) simplification by reducing the number of independent variables starting with the one-dimensional steady case and moving by alternate paths to the full unsteady three-dimensional case; (2) reducing the number of dependent variables in such simplified cases by dimensional analysis; (3) reducing the number of parameters that vary with space or time by assuming some of the parameter set to be constant in space or time or both; (4) simplifying the basic equations by either omitting certain terms as in such approaches as kinematic wave approximation and the diffusion analogy or by linearising the complete equation and thus availing of the powerful tools applicable in linear analysis. The ability of such simplified analytical approaches to represent the more complex prototypes without serious error is remarkable and sometimes paradoxical.

The question then arises as to whether any fundamental principles can be applied over the wide range of differing hydrologic scales from motion at a continuum point $\left(10^{-5} \mathrm{~m}\right.$. to the global water balance $\left(10^{8} \mathrm{~m}\right.$.). Hydrologists are lucky that in progressing from the continuum scale to the global scale the equation of continuity can be integrated in order to move from a lower scale to a higher scale. This useful result occurs because the equation of continuity can be written in a linear form which contains no empirical coefficients. None of the other basic equations of hydrology possess these two properties and hence we can identify the equation of continuity as the fundamental equation of hydrology and its validity 


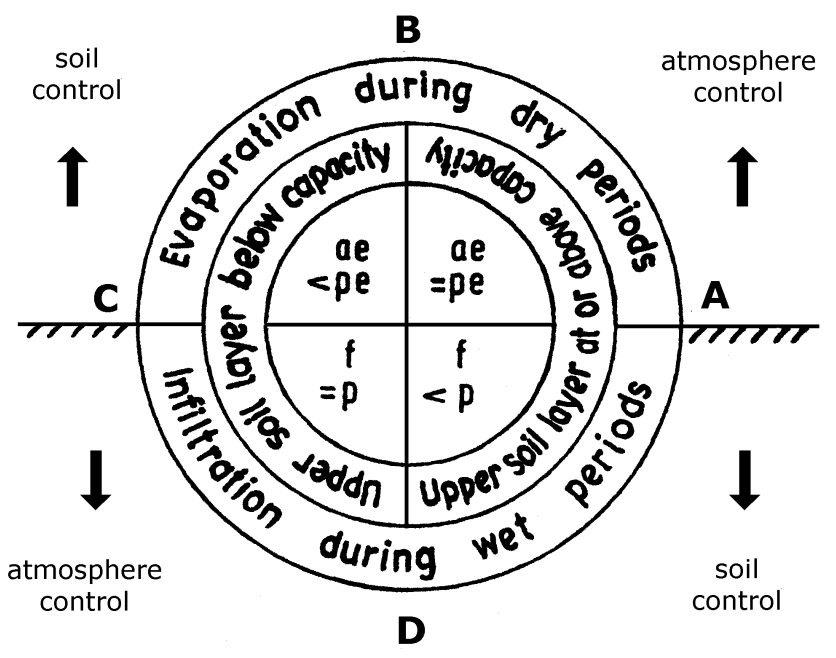

Fig. 3. Control of surface fluxes.

as the fundamental theorem of hydrology. The basic requirement in hydrologic analysis is to satisfy this equation and then to tackle the problem of the remaining equations which are non-linear.

\section{Role of surface fluxes}

A big divide in hydrology is between the fields of surface water hydrology and of subsurface hydrology. This natural division arises because of the key role of the hydrologic fluxes at the surface of the ground on the switching of the control of these fluxes between the atmosphere and the soil as shown in Fig. 3. If rainfall continues for a sufficient length of time, the surface of the soil becomes saturated and the surface of the vegetation retains water (point A in Fig. 3).

If the rainfall ceases, the upward flux of evapotranspiration occurs at the potential rate. As long as this lasts the surface flux would be subject to atmospheric control. When the surface moisture falls below saturation (point B), the control switches to the upper soil layer which controls the rate of actual evapotranspiration which is less than the potential rate.

A renewal of rainfall (point $\mathrm{C}$ ) will occur in a period during which the surface of the soil is unsaturated and the rate of infiltration will be equal to the rate of precipitation and the downward flux will again be atmosphere controlled. The surface moisture content $c$ will increase until ponding occurs (point $\mathrm{D}$ ), after which the infiltration rate will be less than the precipitation rate and the rate of infiltration will become soil controlled.

Such a switching of control represents a concentrated nonlinearity which complicates the combination of the individual hydrological processes of subsurface flow and surface flow. The variation of the soil water profile during these four phases will depend on the variation of the hydraulic diffusiv-

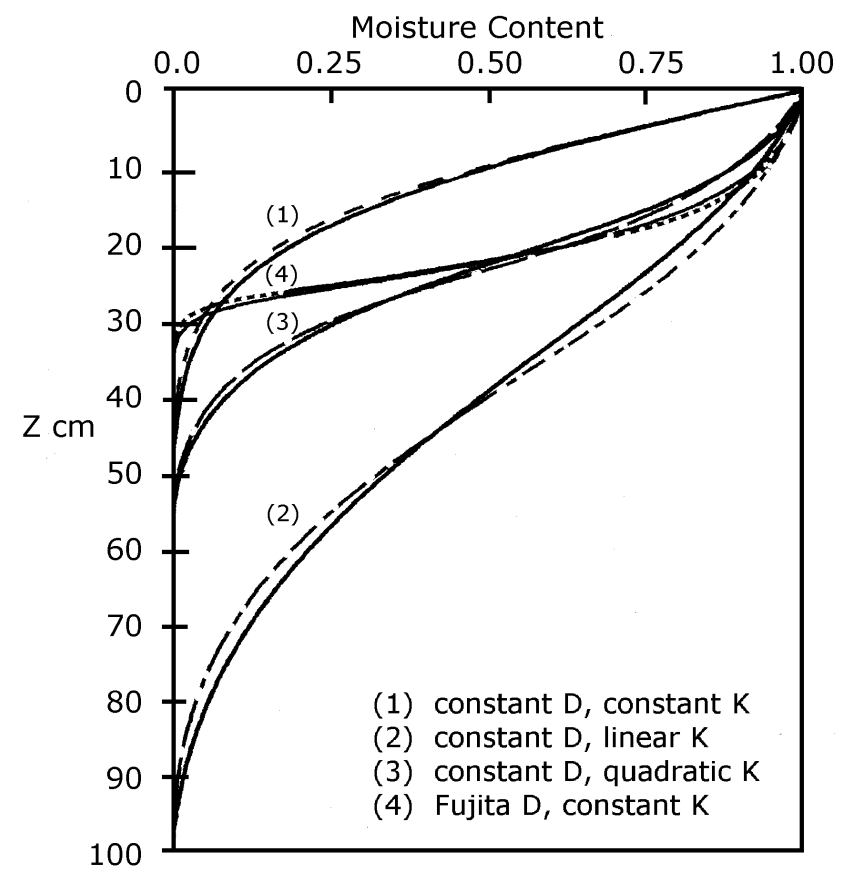

Fig. 4. Profiles at ponding.

ity $(D)$ and the hydraulic conductivity $(K)$ as functions of the local moisture content.

For a limited number of pairs of functions $D(c)$ and $K(c)$ the soil profile for constant rainfall into an unsaturated semiinfinite soil profile, both the shape of the soil profile and the time to surface ponding can be determined analytically (Wang and Dooge, 1994). If we compare this profile at ponding for such atmosphere-controlled conditions with the same volume of soil moisture content under the assumption of instantaneous ponding, we find that the profiles are remarkably similar though they vary greatly dependent on the assumptions in regard to $D(c)$ and $K(c)$. The comparison for four such cases is shown on Fig. 4 as described in Dooge and Wang (1993). Thus as we proceed into a following period of soil-controlled infiltration under ponded conditions (lower right quadrant in Fig. 3) the differences will become less and less and ultimately can be assumed to be the same for all practical purposes.

The result described in the last paragraph indicates that the rate of infiltration during both the atmosphere-controlled and soil-controlled phases can be modelled by the solution for ponded infiltration with an appropriate adjustment for the time to ponding (Kuhnel et al., 1990). This result justifies the concentration on the case of initial ponding conditions by J. R. Philip in his classical studies on unsaturated flow involving a series solution for infiltration in the form of a power series in terms of the square root of the elapsed time (Philip, 1957; Dooge, 2002). 


\section{Simplification of groundwater flow}

There are also a number of results in regard to saturated subsurface flow which facilitate greatly the simplification of the analysis of this hydrologic process. Thus Dupuit (1863) indicated the advantage of assuming ground water flow towards a well to be horizontal, thus reducing the problem from a two dimensional one to a one dimensional one. Twenty years later this approach was formulated by Forchheimer (1886) in such a way as to take a full advantage of the analysis by potential theory of such hydrologic phenomena.

Over 60 years later, Charnyi (1951) proved theoretically that for steady saturated flow between the vertical boundaries, the use of the Dupuit-Forchheimmer assumption of negligible vertical acceleration, while leading to serious error in the shape of the groundwater profile, predicted exactly the flow at these boundaries. Since hydrology tends to be interested in flows rather than profiles this assumption is certainly worthwhile, at least as a preliminary step in the analysis of groundwater flow.

For the case of unsteady flow in groundwater, the equation becomes non-linear with serious difficulties in its solution. However, Kraijenhoff van de Leur (1958) showed that there was no difference in the predicted outflow based on linearisation in terms of the depth of the water table and the predicated outflow based on linearization in terms of the water table $(h)$ or in the square of this depth $\left(h^{2}\right)$. He showed that in either case the impulse response of a simple groundwater profile would be given by a highly convergent series of exponential terms in terms of the ratio of the elapsed time to a single reservoir coefficient incorporating all four parameters of the regular drainage system.

In the case of considerable variations in permeability, it is possible to set limits to the solution for groundwater flow. Matheron (1965) showed that for the case of DupuitForchheimer flow, the average permeability always ranges between the harmonic mean and the arithmetic mean of the local varying permeabilities whatever the spatial correlation of the permeability and whatever the number of space dimensions. Matheron also showed that if the probability distribution of the local permeabilities could be assumed to be log-normal, then for the case of two-dimensional flow the average permeability is exactly equal to the geometric mean of the local permeability. This example illustrates the ability of linear analysis to set limits to the effect of the variability of a key parameter.

\section{Overland flow}

A key element in surface runoff is that of overland flow. Overland flow is particularly important in such areas as urban flood hydrology, the drainage design of roads and airport runways, and the generation of surface runoff in natural catchments with soils of low permeability.
The initial approach to this problem was made by assuming that the outflow at the downstream end was proportional to some power of the storage on the surface. This assumption involves both the replacement of the general unsteady case by a succession of steady states and the application of the kinematic wave approach. This simplifying assumption was applied to natural catchments by Horton (1938) and to paved surfaces by Izzard (1944). The Horton-Izzard approach is essentially a simplification obtained by adopting the kinematic wave approximation which neglects the small acceleration terms in the full dynamic equation and retains only the non-differential bottom slope and friction slope. It gives a reasonable first approximation and is much simpler than the solution involving the complete dynamic equation.

For the two-dimensional case of overland flow resulting from uniform inflow along the slope the dynamic equation is simplified to a power relationship at all times between the outflow $(q)$ and the storage $(S)$ :

$q=a S^{c}$,

where the parameter $c=3 / 2$ for a wide outflow channel with Chezy friction and $c=5 / 3$ for a wide outflow channel with Manning friction. The combination of this simplified dynamic equation with the continuity equation

$\frac{d S}{d t}=q_{e}-q$,

where $q_{e}$ is the rate of inflow and consequently the ultimate state rate of outflow. Equation (1b) can be expressed in dimensionless form as

$d\left(t / t_{c}\right)=\frac{d\left(S / S_{e}\right.}{1-\left(S / S_{e}\right)^{c}}$,

where the characteristic time $\left(t_{c}\right)$ is given by

$t_{c}=\left(\frac{S_{e}}{q_{e}}\right)=\left(\frac{1}{a S_{e}^{c-1}}\right)=\left(\frac{1}{a q_{e}^{c-1}}\right)^{1 / c}$.

The integral of Eq. (1c) has a closed form solution for all rational values of the parameter $c$.

For the two limiting cases of $c=1$ and $c=2$ the closed form solution of Eq. (1b) of elapsed time $(t)$ as a function of downstream runoff $(q)$ can be inverted to obtain the runoff $(q)$ and as a function of the time.

In the case of the recession following the cessation of inflow it is possible to predict the variation of storage and hence of outflow as an explicit function of the time elapsed since the onset of the recession. In this case we have

$$
\frac{S}{S_{o}}=\left(\frac{1}{1+t / t_{o}}\right)^{\frac{1}{c-1}}
$$

and

$\frac{q}{q_{o}}=\left(\frac{1}{1+t / t_{o}}\right)^{\frac{c}{c-1}}$, 
where the characteristic time $\left(t_{o}\right)$ is based on the parameter $a$ and $c$ and the value of either the storage $\left(S_{o}\right)$ or the outflow $\left(q_{o}\right)$ at the beginning of the recession.

Figure 5a shows typical results from a carefully designed laboratory experiment by Amorocho and Orlob (1961), showing the cumulative runoff against time for three different values of uniform artificial rainfall. The comparison of the overland flow for any given elapsed time $(t)$ for the three different values of inflow clearly shows that these values are not proportional to the rate of inflow, i.e. that the system is non-linear.

However, the relationship can be made dimensionless by multiplying the discharge by a characteristic time $\left(t_{c}\right)$ and dividing by the corresponding characteristic volume $\left(V_{c}\right)$ and dividing the elapsed time by the same characteristic time. When the data in Fig. 5a are treated in this fashion the three non-linear responses of Fig. 5a plot along a single curve as shown in Fig. 5b. The characteristic time in this case was taken as the time at which the outflow reaches a particular percentage of the constant inflow rate.

If we assume that the laboratory system represents a wide rectangular channel with Manning friction then the characteristic time should be inversely proportional to the characteristic discharge to the power of two-fifths (i.e. 0.4). An analysis of the data by Amorocho and Orlob indicates that the characteristic time is inversely proportional to the rate of constant inflow to the power of 0.3997. In this case the progress is made not through linearization but through the appropriate use of dimensional analysis in which parameter values are combined with dependent variables.

The integral of Eq. (1c) above is encountered elsewhere in hydrology, notably in relation to non-uniform steady flow in open channels and to the long-term water balance. It was used by French hydraulicians of the 19th century to solve special cases of steady non-uniform flow in prismatic channels and was generalised and the results calculated and tabulated by Bakhmeteff $(1912,1932)$.

The same integral has been suggested by Bagrov (1953), in the analysis of the sensitivity of the evaporation ratio $\left({ }^{A E} / P E\right)$ to the humidity index $(P / P E)$ of a catchment or a region. The solution of this integral allows us to calculate the sensitivity of the long term evaporation ratio to a change in either long term precipitation $(P)$ or long term potential evaporation $(P E)$ for the Bagrov family of curves of actual evaporation (Dooge, 1992b).

\section{Flood routing in channels}

The movement of a flood wave down a channel reach involves both translation and subsidence. The travel time or lag is represented by the difference between the first moments about the origin of the upstream inflow and the downstream outflow. The modification of the shape of the flood wave can

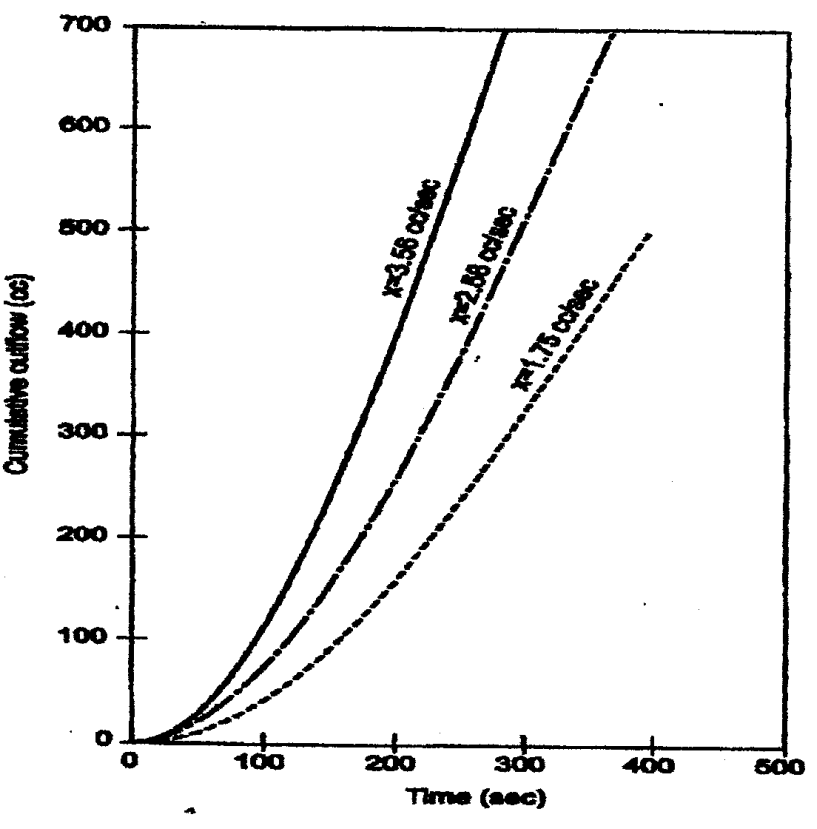

\section{Typical Results of Laboratory Studies}

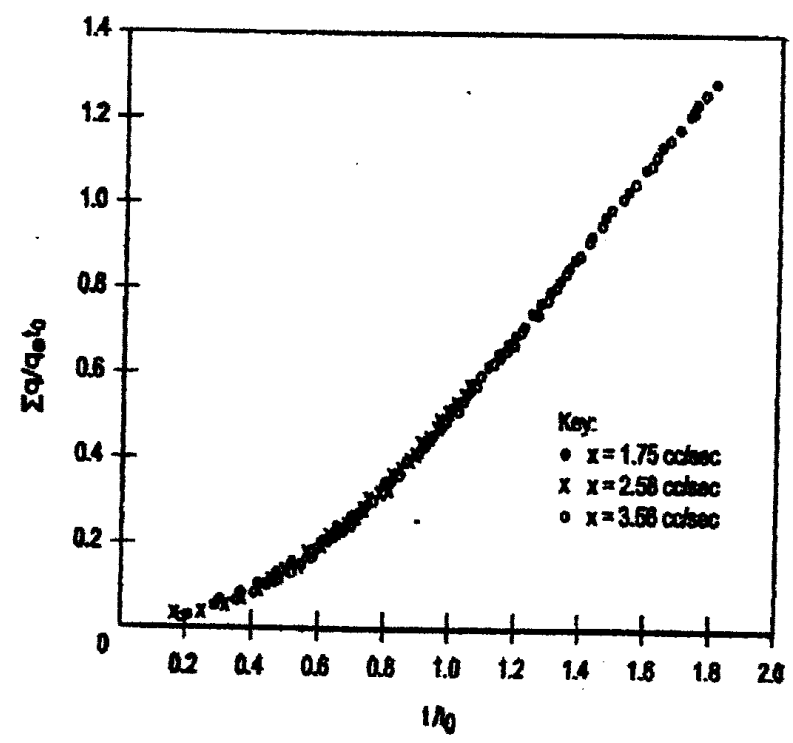

Fig. 5. (a) Laboratory study of overland flow. (b) Dimensionless plot of laboratory results.

be characterised by comparing the higher moments of the two hydrographs about their respective centres.

A starting point for the analysis of these factors is the linearization of the basic St. Venant equation for unsteady flow as applied to unsteady downstream flow in a prismatic channel. This approach studies first the linear channel response (LCR) due to an impulse at the upstream end of a semi- 


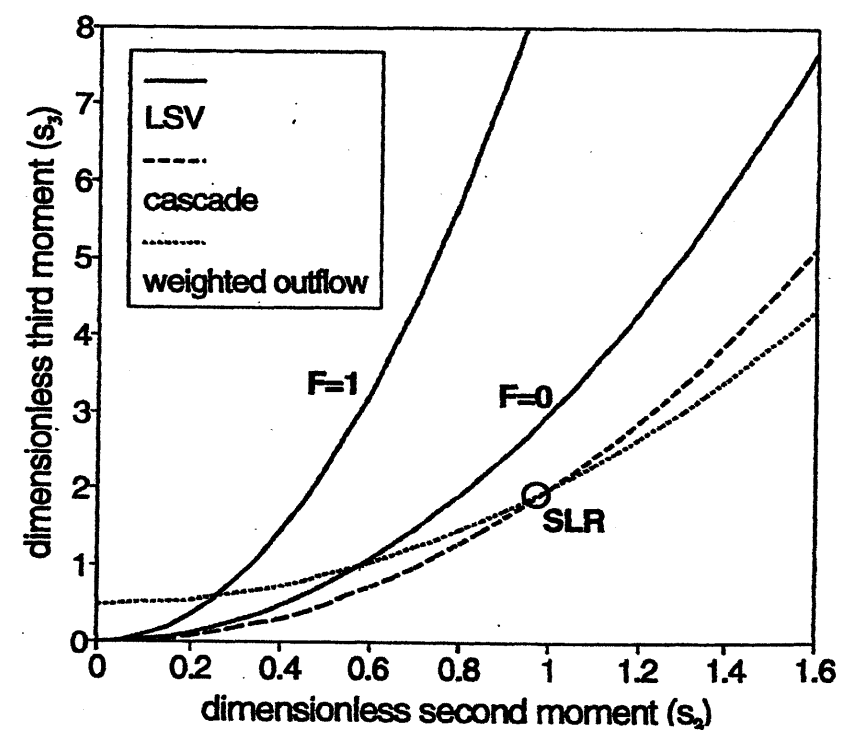

Fig. 6. Shape factors for 2-parameter models.

infinite prismatic channel and then derives analytically the values of the moments $\left(U_{R}^{\prime}\right)$ and the related cumulants $\left(k_{R}\right)$ of this linear channel response (Dooge and Harley, 1967; Napiorkowski, 1992).

The translation of the wave due to an upstream impulse is given by the first moment of the linear channel response which is

$k_{1}=U_{1}^{1}=\frac{x}{m u_{o}}$,

where $x$ is the distance downstream of the point of input; $m$ is the index of non-linearity which has the values $m=5 / 3$ for a wide rectangular channel with Manning friction; and $u_{o}$ is the velocity for the reference condition used as the basis of linearization. This expression holds for all values of the Froude number $\left(F_{o}\right)$ of the reference condition and corresponds to the lag predicted by the kinematic wave solution for the linearised case.

Any regular shape can be characterised by the values of the moments about the centre which are the coefficients in the polynomial defined by the Laplace transform of the linear channel response (LCR). This solution can be used as the basis of comparison of the conceptual models of channel flow used in the simulation of catchment runoff.

The translation, dispersion and skewness of the linear channel response can be represented respectively by the first moment about the origin $\left(U_{1}\right)$ and the second and third moments about the centre $\left(U_{2}, U_{3}\right)$. The three parameters represented by these three moments can be reduced to the two dimensionless parameter obtained by reducing the second and third moments to dimensionless shape factors $\left(s_{2}\right.$ and $\left.s_{3}\right)$ by expressing them as a ratio to the appropriate power of the first moment as follows:

$s_{2}=\frac{U_{2}}{\left(U_{1}^{\prime}\right)^{2}}$

and

$s_{3}=\frac{U_{3}}{\left(U_{1}^{\prime}\right)^{3}}$

The relationship between these two dimensionless shape factors for the linearised solution is shown on Fig. 6 .

It can be shown that for the linear channel response to an impulse at the upstream end of a prismatic channel, the relationship between $s_{3}$ and $s_{2}$ is given by

$s_{3}=\Phi_{3}\left(m, F_{o}\right)\left(s_{2}\right)^{2}$,

where $m$ is the parameter in the relationship between the discharge $(Q)$ and the area of flow $(A)$ in the power relationship

$Q=k A^{m}$

and $F_{o}$ is the Froude number at reference conditions.

For the Froude Number $F_{o}=0$, the relationship for all values of the non-linearity index $\mathrm{m}$ is given by

$s_{3}=3\left(s_{2}\right)^{2}$,

while for the upper limit of $F_{O}=1$, the relationship for a wide rectangular channel with Manning friction (i.e. $m=5 / 3$ ), the relationship is given by

$s_{3}=15\left(s_{2}\right)^{2}$

The wide range between these two limiting solutions in the $s_{3}-s_{2}$ plane indicates that only a conceptual model with 3 or more parameters could represent both of the dimensionless shape factors $\left(s_{2}\right.$ and $\left.s_{3}\right)$ with acceptable accuracy.

\section{Comparison of conceptual models}

It is interesting to compare the performances of the classical 2-parameter conceptual models in fitting the complete solution. This is done on Fig. 6 for the classical flood routing methods. For the Muskingum method due to McCarthy (1939), the relationship between the dimensionless shape factors $s_{3}$ and $s_{2}$ is given by:

$s_{3}=\frac{3 s_{2}^{2}+1}{2}$,

which overlaps the solution region for values between $x=0.22$ and $x=0.40$ which corresponds to the range of values used empirically in classical hydrology. For the lag and route method due to Meyer (1941), the relationship is given by:

$s_{3}=2\left(s_{2}\right)^{3 / 2}$, 
which lies within the region of the complete solution (as shown by a dashed line on Fig. 6) for values of the ratio of the lag parameter $(T)$ to the reservoir parameter $(K)$ greater than 0.5 . This lower range of overlap corresponds to values of $s_{2}$ between 0 and 0.44 and thus is also appropriate to comparatively short channels.

In contrast for the cascade of characteristic reach reservoirs due to Kalinin and Milyukov (1957) the relationship

$s_{3}=2 s_{2}^{2}$

clearly lies completely below the lower limit of the complete solution given by Eq. (4a) above.

The lag and route model can be combined with either the Muskingum model or the Kalinin-Milyukov model to produce the 3-parameter models of the lagged Muskingum model and the lagged Kalinin-Milyukov model, respectively. These 3-parameter models can be calibrated by equating the second and third order moments to the relevant data to produce the shape of the response function and then adjusting the corresponding lag to conform to the measured lag by introducing an additional time shift.

The efficiency of the above 3-parameter conceptual models can be evaluated by using cumulants rather moments and equating the second and third cumulants (which are equal to the second and third moments) of the conceptual model to the data. The relationship between the dimensionless fourth cumulant and the dimensionless third cumulant for the complete linear solution is given by

$f_{4}=\frac{k_{4}}{\left(k_{2}\right)^{2}}=\frac{U_{4}}{\left(U_{2}\right)^{2}}-3=\psi\left(m, F_{o}\right)\left(f_{3}\right)^{2}$

For $F_{o}=0$ (i.e. the diffusion analogy), the upper limit of the solution region is

$f_{4}=\frac{5}{3}\left(f_{3}\right)^{2}$

and the lower limit corresponding to $F_{O}=1$ is given by

$f_{4}=\frac{4}{3}\left(f_{3}\right)^{2}$

These two limiting curves shown on Fig. 7 (which are independent of the value of the non-linearity index $m$ ) define a relatively narrow region and the aim becomes that of finding a model that lies within this region.

The lagged Muskingum lies within the region only for values of $x$ less than 0.22 and only covers the upper right hand section of the region.

In contrast the lagged Kalinin-Milyukov method (represented by the 3-parameter gamma distribution) is given by

$f_{4}=\frac{3}{2}\left(f_{2}\right)^{2}$

and this lies cosily between the two limiting lines of the complete solution for all of that region. Because of the closeness of the latter limiting lines the error in using a lagged cascade

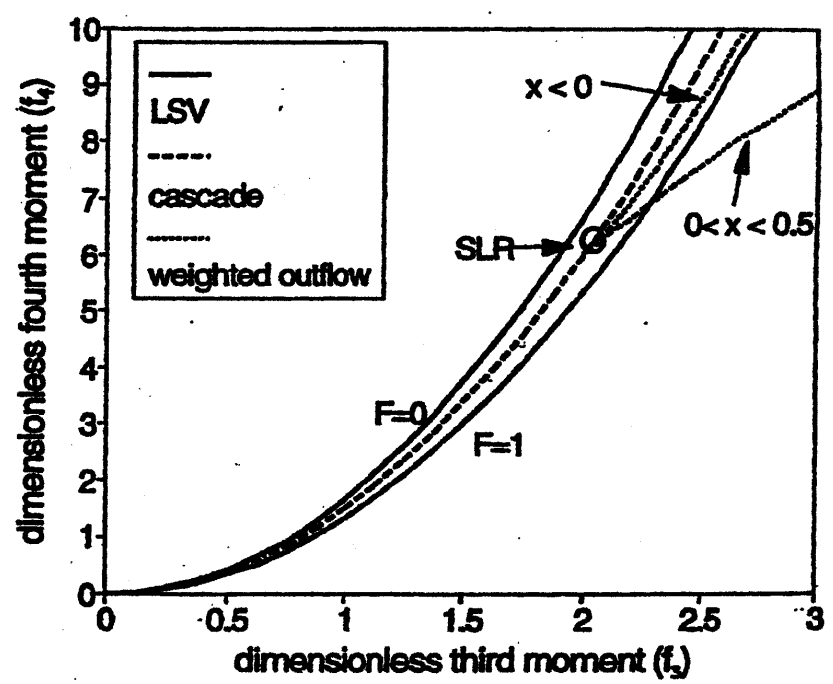

Fig. 7. Shape factors for 3-parameter models.

of equal linear reservoirs is $11 \%$ or less for all values of $F_{o}$ between 0 and 1 . This is bringing us into the neighbourhood of acceptable error in practical hydrology.

\section{Total catchment runoff}

The rational method for determining the peak discharge based on the concept of the time of concentration was applied to natural catchments by Mulvany (1851) and Chamier (1897) and to urban catchments by Kuichling (1889) and Lloyd-Davies (1906). This approach was extended to the prediction of the total hydrograph through the introduction of the concept of the time-area-concentration curve by Hawken and Ross (1921). In the 1930s, Zoch proposed modifying this approach by routing the time-area-concentration curve through a single linear reservoir (Zoch, 1934, 1936, 1937). This method was developed by Turner and Bourdoin (1941) and by Collins (1939). O'Kelly (1955) showed that there was only a small difference in the shape of the derived unit hydrograph if the Clark method was compared with a routed isosceles triangle.

Around the same time that Kalinin and Milyukov (1957) applied the cascade model to flood routing, Nash (1958) independently proposed the same model for the case of total surface response. Figure 8 shows the relationship between the shape factors $s_{2}$ and $s_{3}$ for three different conceptual models: a routed rectangle (A), a routed isosceles triangle (B), and a cascade of equal linear reservoirs (C). The variation in the position of the line representing these quite different models is remarkably small thus making the choice between them a matter of convenience (Dooge, 1973, 2003).

One would expect that in moving from the case of a single uniform channel reach to that of the complex network of a total catchment, that this more complex system would require 


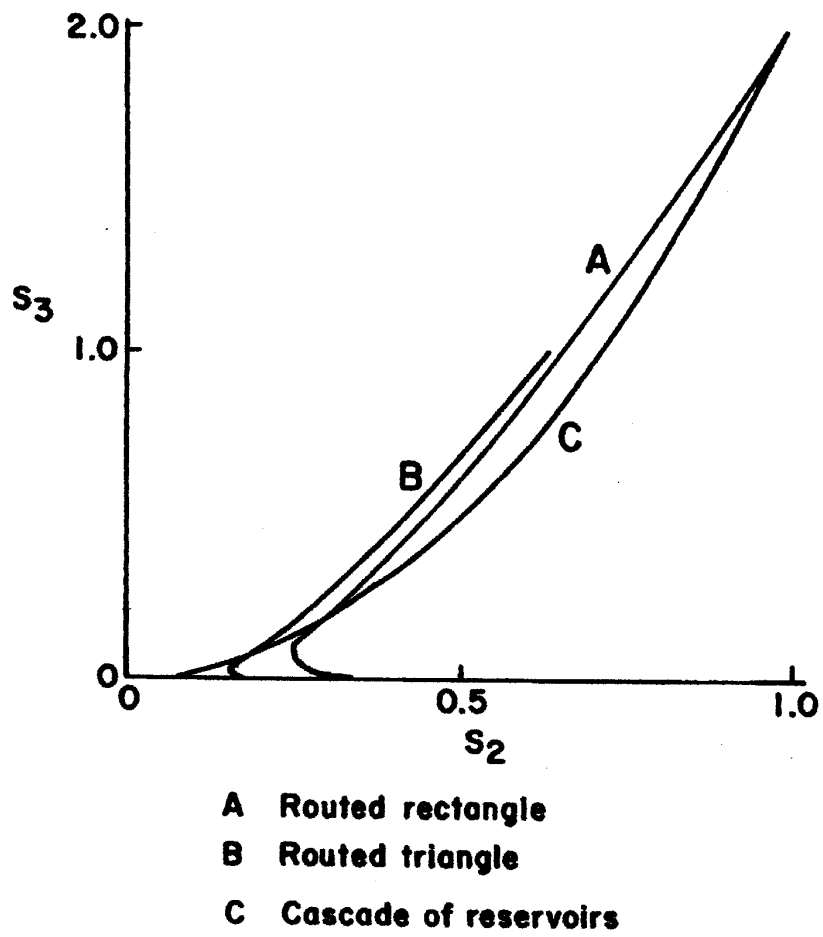

Fig. 8. Comparison of conceptual models.

a conceptual model with a higher number of parameters. In fact, we find that if we take the concept of the geomorphological unit hydrograph (Rodriquez-Iturbe and Valdez, 1979), based on Horton's laws of catchment morphology, into account then in fact an accurate representation can be obtained with the original two parameter model.

Chuta and Dooge (1990) carried out a series of 1100 Monte Carlo tests on a linear geomorphological unit hydrograph based on the original concept of the geomorphological laws of drainage basin networks due to Horton (1945) and the proposal by Rodriguez-Iturbe and Valdez (1979) to simulate the unit hydrograph of such Horton catchments by assuming an exponential delay time (i.e. a linear reservoir).

These experiments covered a range of branching ratios $\left(R_{B}\right)$ between 2.5 and 5.0, a range of length ratios $\left(R_{L}\right)$ between 1.5 and 4.1 and a range of area ratios $\left(R_{A}\right)$ between 3.0 and 6.0. As shown in Fig. 9 the plotted points cling closely to the line for a Nash cascade of equal linear reservoirs without the additional lag adjustment required in the case of flood routing in the simple case of a uniform prismatic channel. The range of the cascade model that matches the third order GUH is that which corresponds to values of $\mathrm{n}$ between 2 and 3 in the Nash model.

This work was later extended by Shamseldin and Nash $(1998,1999)$ to cover catchments of all orders between 2 and 5 as well as the original case of a third order catchment examined by Chuta and Dooge (1990). The same close correspondence between the shape factors for the GUH and the

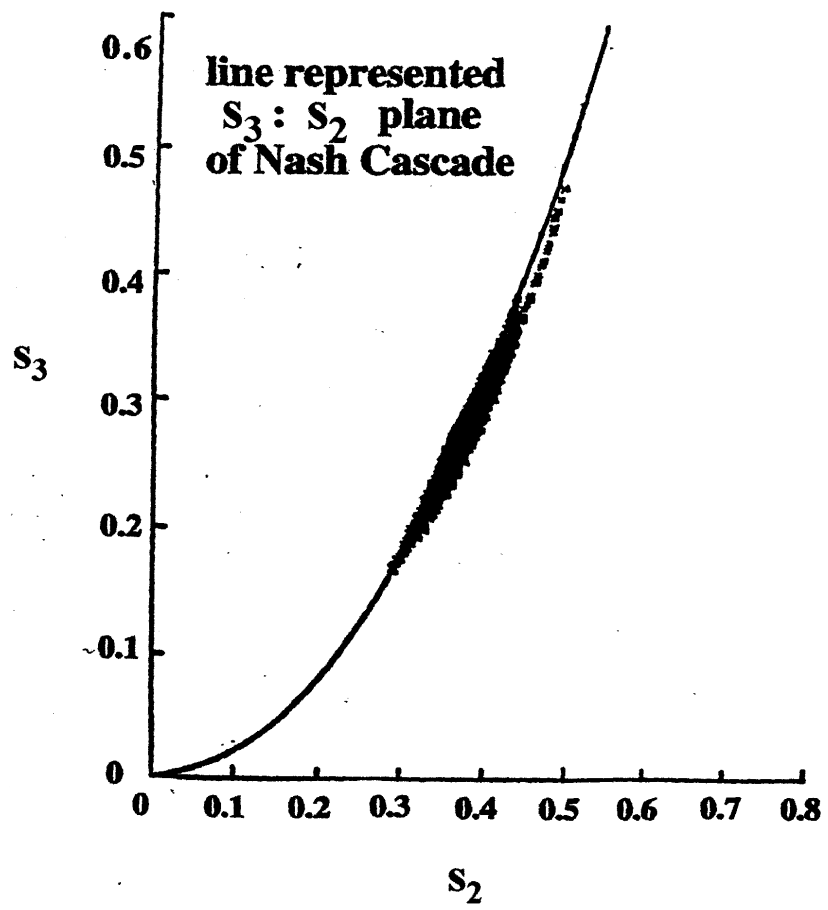

Fig. 9. Shape factors for GUH.

2-parameter mode of a cascade of equal linear reservoirs is obtained. In this case from a GUH of order 2 to one of order 5 , the range of value of $\mathrm{n}$ in the corresponding cascade model is between 1 and 5 .

\section{Extension to uniform non-linearity}

While the results described above indicate the general usefulness of a cascade of equal linear reservoirs as a conceptual model in hydrology, the results for channel flow and for catchment response are limited by the restrictive basic assumption of linearity. In the case of overland flow the basic assumption is that the differential terms in the momentum equation which are of an order of magnitude smaller than the non-differential terms representing channel slope and friction slope can be neglected (i.e. the non-linear kinematic wave approach). In this case the runoff from different events is not proportional to the input as indicated by Fig. 5a. However, for any fixed value of the non-linearity parameter $c$ in Eq. (1a), the response to similar events of different intensities can be combined by the use of a single dimensionless relationship as shown in Fig. 5 b.

The latter simplification indicates that a similar approach might prove productive in the case of the more complicated cases of channel flow and total catchment response. Over 30 years ago, the present author proposed that this problem be tackled by considering the non-linear conceptual model of a cascade of equal non-linear reservoirs (Dooge, 1967). 
In such a model the combination for any individual nonlinear reservoir of the continuity equation and the non-linear storage - discharge relationship gives the equation for the ith storage element as

$\frac{d S_{i}}{d t}=a\left(S_{i-1}\right)^{c}-a\left(S_{i}\right)^{c}$

Using any convenient reference volume $S_{o}$ and the related reference time appropriate to this non-linear relationship given by

$t_{o}=\frac{S_{o}}{Q_{o}}=\frac{1}{a S_{o}^{c-1}}=\left(\frac{1}{a Q_{o}^{c-1}}\right)^{1 / c}$

this basic equation can be written for each successive value of $i$ as

$\frac{d\left(S_{i} / S_{o}\right)}{d\left(t / t_{o}\right)}=\left(S_{i-1} / S_{o}\right)^{c}-\left(S_{i} / S_{o}\right)^{c}$

If the inflow at the upstream end $I(t)$ into the first storage element is multiplied a characteristic time $\left(t_{o}\right)$ and the product divided by a characteristic volume $\left(S_{o}\right)$ to obtain a dimensionless input

$\frac{I(t) \cdot t_{o}}{S_{o}}=I^{\prime}\left(t / t_{o}\right)$

then the solution of Eq. (10c) will have the form

$$
\left(\frac{S_{1}}{S_{0}}\right)=f_{1}\left(t / t_{o}\right)
$$

for the upstream reservoir in the cascade and successive solutions of Eq. (11c) will all be of the form

$$
\left(\frac{S_{i}}{S_{o}}\right)=f_{i}\left(t / t_{o}\right)
$$

For a cascade of $n$ such equal non-linear reservoirs the outflow from the system will be given in the dimensionless form

$$
\begin{aligned}
& \frac{Q(t) \cdot t_{o}}{S_{o}}=\left(\frac{S_{n}}{S_{o}}\right)^{n} \\
& =\left[f_{n}\left(t / t_{o}\right)\right]^{c}
\end{aligned}
$$

and will be the same for every similar input that belongs to the class of functions which differ in average intensity and time scale but are identical when plotted in the dimensionless form of Eq. (13). This restriction is less constraining than might appear at first sight since large flood producing storms tend to have a duration which varies inversely with the intensity of the rainfall.

A classical case in hydrologic literature of non-linearity in catchment response is due to Minshall (1960) who compared unit hydrographs derived for a 27 acre catchment for five different storms where the rainfall varied from 0.95 inches per hour to 2.65 inches per hour. The derived unit hydrographs are shown in Fig. 10a from which it could be seen that a

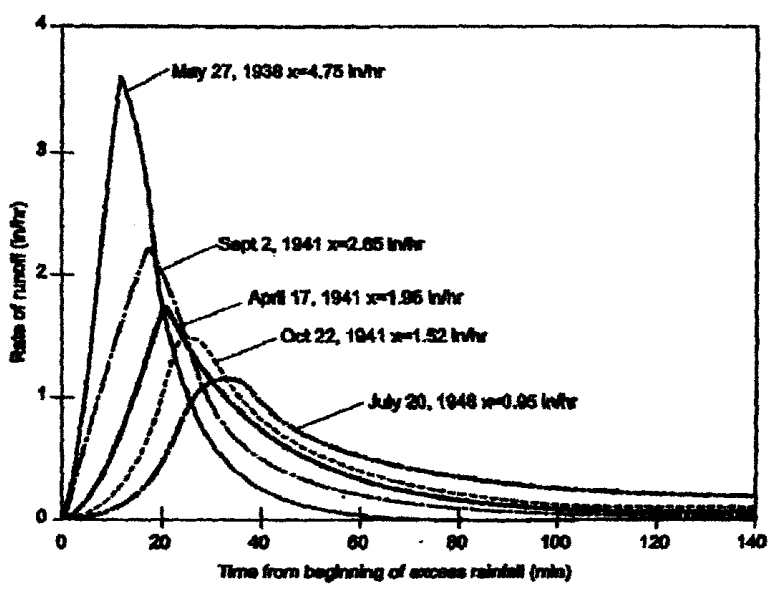

Hydrographs for 22 acre Catchment

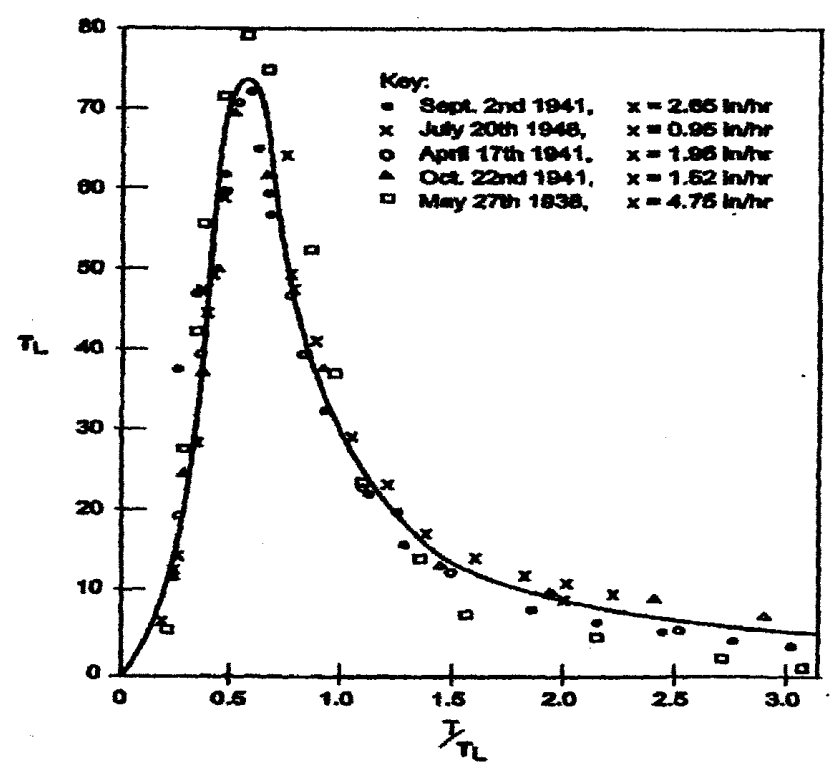

Dimensionless Hydrograph

Fig. 10. (a) Non-linear unit hydrographs. (b) Dimension plotting of non-linear hydrographs.

normal unit hydrograph approach of transferring derived unit hydrograph from one storm to predict the runoff from a storm of distant intensity does not hold in this particular case.

It is not possible to make as precise an analysis of this case as for the laboratory data of Amorocho and Orlob (1961) discussed in Sect. 5 above. However, it is possible to use a characteristic time $\left(t_{o}\right)$ and characteristic storage $\left(S_{o}\right)$ in Eq. (13b) to produce a dimensionless unit hydrograph. In the case of Minshall's data this results in Fig. 10b which shows that the use of this dimensionless hydrograph in combination with 


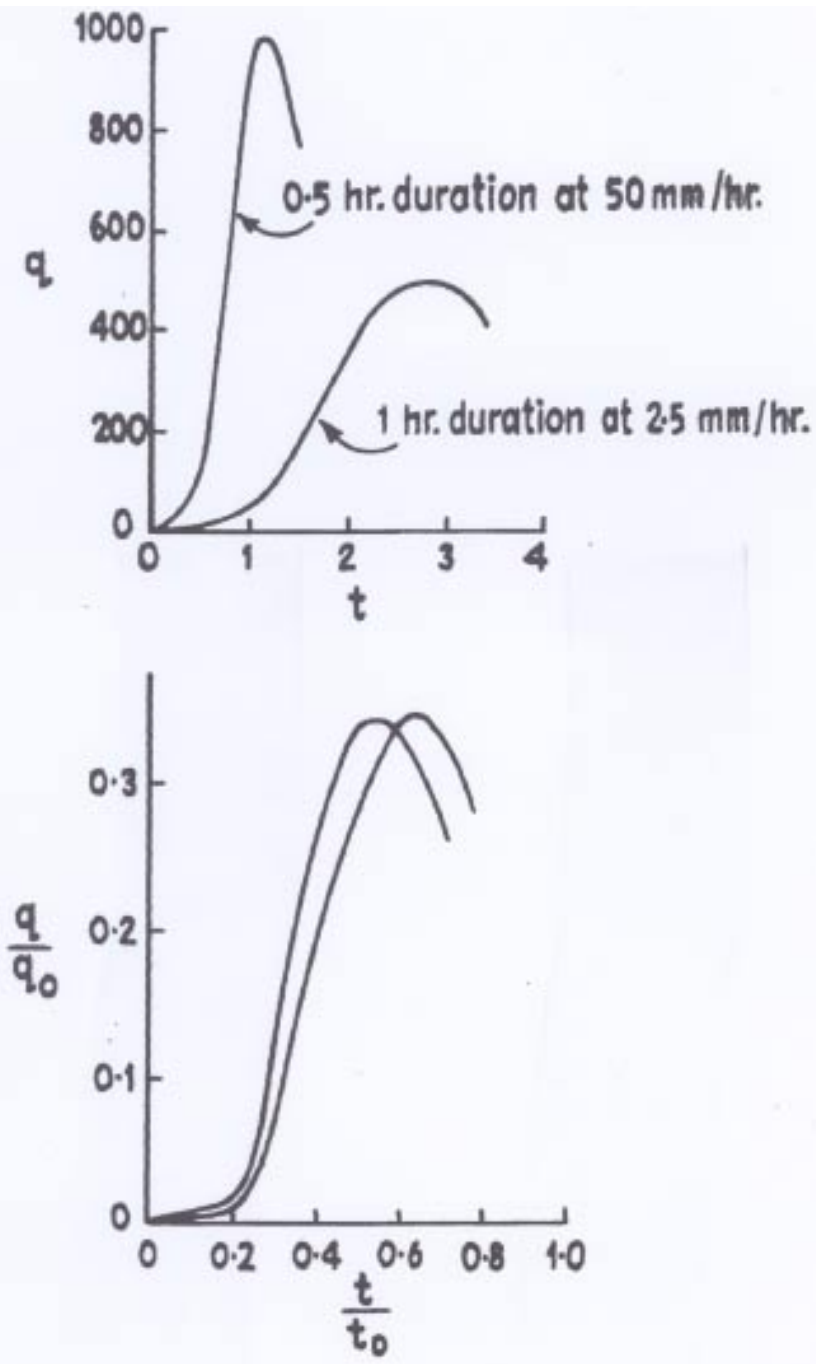

Fig. 11. (a) Non-linear simulation. (b) Dimensionless plotting of simulation.

the relationship between the characteristic time and some intensity characteristic inflow, would allow a transfer between storms of sufficient accuracy for most hydrological purposes.

Another interesting example is contained in the computer simulation of catchment outflow based on the full non-linear dynamic equation. Figure 11a shows two of the non-linear simulations which satisfy the relationship of Eq. (11) since they involve similar inputs with the intensity of input inversely proportional to the duration.

When these two outflow hydrographs are scaled similarly to Eq. (13b), the resulting dimensionless outflow hydrographs shown on Fig. $11 \mathrm{~b}$ are close approximations of each other with a small time shift. This time shift has a parallel in the time shift required in the linearised case where a 3parameter gamma distribution is required to bring the error of using the conceptual model within reasonable approximation of the complete linearised solution.

\section{Deterministic and stochastic similarities}

The review of the deterministic approach to hydrologic analysis outlined above has its counterpart in the stochastic approach to the subject. Reference was made at the beginning of the paper, not only to the separation for purposes of analysis between the deterministic and stochastic components of hydrologic response but also to the argument by Velikanov (1962) about the importance of the gamma distribution for multi-component stochastic systems. The emphasis on the gamma distribution in both stochastic and deterministic hydrologic systems is of importance. It suggests that progress in both areas would benefit if they were considered as complementary rather than separate fields of investigation. This is exemplified in the close approximation of the linear geomorphic unit hydrograph by the gamma distribution which is applicable in other areas of both deterministic or stochastic behaviour of natural catchments.

If we move to non-linear analysis, the question arises whether there is a link between the deterministic analysis of uniform non-linearity (Dooge, 1967) and the formulation of the non-linear gamma distribution by Kritski and Menkel (1948). These and similar questions pose interesting problems deserving of attention by the present generation of young hydrologists.

\section{Conclusions}

G. Pegram in his comment remarks "a concluding paragraph is noticeably absent". The present section is an attempt to remedy that particular fault in the original version by summarising significant features of the chief results described and suggesting areas for future research of a similar character both in hydrological analysis and hydrological prediction as well as responding to the comments in the discussion.

In hydrologic analysis certain phenomena recur both in rigorous analysis and in approximate analysis for prediction purposes. If the analysis is conducted in terms of discharge $(Q)$ and the area of flow $(A)$ as state - space variables then the continuity equation is linear and is therefore parameter free at all scales. A. Montanari in his comment refers to the question of relaxing this assumption in the simulation of catchment runoff because of the uncertainties involved in such cases. The author is of the opinion that the principle of continuity should be retained as an anchor rather than compromised by uncertainties in data and in parameters.

Less fundamental but intriguing is the efficiency of the gamma distribution both in the linear analysis of channel flow and of the geomorphic unit hydrograph and as the asymptotic distribution for a large number of interacting skewed statistical distributions. Equally interesting is the recurrence of the Bakhmeteff-type integral from non-uniform steady open channel flow in the analysis both of overland 
flow which occurs at a small scale and in studying the effect of climate change on water balance at a much larger scale.

The use of measured data from one event on a particular catchment to studying other events (actual or predicted) on the same catchment or to similar events in an ungauged catchment is a key problem in applied hydrology. It is important to be clear about the assumptions involved. If the same event is repeated exactly on the same catchment, then the only basic requirement for a direct transfer of the measured runoff is that of time-invariance in regard to the governing parameters. If the events are not identical, an attempt can be made to solve the problem by assuming both time-invariance and linearity which are the two fundamental assumptions of the unit hydrograph approach to catchment runoff (Dooge, 1959). In the case of overland flow and of small-scale catchment runoff the assumption of linearity is clearly invalid as shown on Figs. 5a and 10a. If, however, the transfer process is restricted to events where the inputs are the same when plotted in dimensionless form, then the transfer can be made as shown in Figs. 5b and 10b. Such cases of uniform non-linearity can be handled for similar events by established unit-hydrograph techniques supplemented by a knowledge of the degree of non-linearity which can be derived from the recession hydrograph in the case of overland flow and from the comparison of a number of different events in the case of catchment runoff.

It is hoped that the results described in this contribution are sufficiently interesting and used to encourage further research along the same lines. The comment by J. P. O'Kane is an excellent example of such an extension to cover the question of hysteresis in subsurface unsaturated flow. This concerns a key area in the hydrological cycle because of switching of the control of surface fluxes between atmosphere control and soil - control. In the case of channel flow, it would be interesting to extend the linearisation about a steady condition to linearisation about the non-linear kinematic response to a specific form of input. It would be interesting to find out the effect of such a change in predicting a closer approximation to the output predicted by the non-linear solution and on reducing the time lag required to match the first moment. In the case of the catchment runoff, it would be interesting to derive the non-linear equivalent of comparing the shape factors of the geomorphic unit hydrograph with the gamma distribution.

There is thus plenty of scope for a younger generation of hydrologists to continue the approach based on careful simplification. It is to be hoped that some of them would find it more satisfying to derive simpler conceptual models through approximate analysis rather than seek closer approximations to uncertain data by using ever more complex models involving a further extension of the number of parameters to be calibrated.
Acknowledgements. The author is grateful to G. Pegram, A. Montanari, J. P. O'Kane and H. Savenije for their comments on the original contribution.

Edited by: H. H. G. Savenije

\section{References}

Amorocho, J. and Orlob, G. T.: Non-linear analysis of hydrologic systems, Water Resources Center, Univ. Calif. (Berkeley), Contrib., 40, 147 pp., 1961.

Bagrov, N. A.: Osrednem mnogoletnem ispraeniz c paverknosti sushi (On the average long term evaporation from the land surface), Meteorologia I Gidrologia, 10, 20-25, 1953.

Bakhmeteff, B. A.: O Neravnomernom Dwijenii Jidkosti v Okritom (On the unsteady movement of liquids in open channels), St. Petersburgh, 1912.

Bakhmeteff, B. A.: Hydraulics of Open Channels, McGraw-Hill, New York, 32 pp., 1932.

Chamier, G.: Capacities required for culvert and flood openings, Proc. Inst. Civil Engineers, 134, 313-323, 1897.

Charnyi, I.A.: A rigorous derivation of Dupuit's formula for unconfined seepage with a seepage surface, Doklady Akademii Nauk, Moscow, 79, 6, 1951.

Chuta, P. and Dooge, J. C. I.: Deterministic derivation of the geomorphic unit hydrograph, J. Hydrol., 117, 81-97, 1990.

Collins, W. T.: Runoff distribution graphs from precipitation occurring in more than one time unit, Civil Eng. G(g), 559-56, 1939.

Dooge, J. C. I.: A General Theory of the Unit Hydrograph, J. Geophys. Res., 64, 2, 241-256, 1959.

Dooge, J. C. I.: A New Approach to Non-Linear Problems in Surface Water Hydrology, Commission on Surface Waters, International Association for Scientific Hydrology, Proceedings of General Assembly of Berne, IAHS Publication No. 76, 409-413, 1967.

Dooge, J. C. I.: Linear theory of hydrologic systems, U.S. Dept. Agr. ARS Tech. Bull. 1468 Superintendent of Documents, Washington, October 1973, 327 pp., reprinted in 2003 by European Geosciences Union, Katlenburg-Lindau, Germany, 1973.

Dooge: J. C. I.: On the Study of Water, Jubilee Lecture to the Exeter General Assembly of IAHS, July 1982, Hydrol. Sc. J., 1.28, 1, 23-48, 1983.

Dooge, J. C. I.: Scale problems in surface fluxes, In: Space and Time Scale Variabilities and Interdependencies in Hydrologic Processes, Edited by Feddes, R. A., Cambridge University Press, 21-32, 1992a.

Dooge, J. C. I.: Sensitivity of runoff to climate change: a Hortonian approach, Bulletin of American Meteorological Society, 73, 1992b.

Dooge, J. C. I.: Searching for simplicity in hydrology, Society lecture to Hamburg General Assembly of European Geophysical Society (April 1995), Surv. Geophys., 18, 5, 511-534, 1997.

Dooge, J. C. I.: Simplification plus rigorous analysis: the modus operandi of John Philip, In: Environmental Mechanic, Water mass and energy transfer in the biosphere, The Philip Volume edited by: Raats, P. A. C., Smiles, D., Warrick, A. W., Geophysical Monograph 129, AGU, Washington DC, 35-45, 2002. 
Dooge, J. C. I. and Harley, B. M.: Linear routing in uniform open channels, Int. Hydrology Symposium, Fort Collins, Proceedings, 1, 57-63, 1967.

Dooge, J. C. I. and Wang, Q. J.: Comment on "An investigation of the relationship between ponded and constant flux rainfall infiltration" by Poulavassilis, A., Kerkides, P., Elnaloglou, S., and Argyrokastritis, I., Water Resour. Res., 27, 7, 1403-1409, 1991, Water Resour. Res., 39, 4, 1335-1337, 1993.

Dupuit, A. J. E. J.: Etude Theoriques et pratiques sur la Mouvement des Eaux dans les canaux decouverts et a travers les terrains permeables, (Theoretical study of the movement of flowing water)m Dunod, Paris, Second edition 1863, 1963.

Forchheimer, Ph.: Über die Ergiebigkeit von Brunnen-Anlagen und Sickerschlitzen, Zeitschrift des Architekten und Ingenieur, (On the flow of wells and groundwater) Vereins zu Hannover, 32, 540-564, 1886.

Hawken, W. H. and Ross, C. N.: The calculation of flood discharges by use of a time-contour plan, Inst. Eng. Aust. J., 2, 85-92, 1921.

Horton, R. E.: The interpretation and application of runoff plot experiments with reference to soil erosion problems, Soil Sci. Soc. Am. Pro., 3, 340-349, 1983.

Horton, R. E.: Erosional development of streams and their drainage basins: hydrophysical approach to quantitative geomorphology, Bulletin of the Geological Society of America, 56, 275-370, 1945.

Izzard, C. F.: The surface-profile of overland flow, Am. Geophys. Un. Trans., 25, 958-968, 1944.

Kalinin, G. P. and Milyukov, P. I.: O raschete reustanovivshegosya dvizheniya vady $\mathrm{v}$ atkrytykh ruslak (on the computation of unsteady flow in open channels), Meteorology I Gidrologiya, Leningrad, 10, 10-18, 1957.

Kraijenhoff van de Leur, D. A.: A study of non-steady groundwater flow with special reference to a reservoir coefficient, Ingenieur, 70, 19, 87-94, 1958.

Kritskii, S. N. and Menkel, M. F.: Vibor tipa trivykh respredeleniya veroyatnstnei rdaya schetov rechnogo stoka (Choice of the type of probability distribution curves of river runoff) Izv AN SSSR Otd Tekhn Nauk, 6, 1984.

Kuhnel, V., Dooge, J. C. I., Sander, G. C., and O'Kane, J. P. J.: Duration of atmosphere-controlled and soil controlled phases of infiltration for constant rainfall at a soil surface, Ann. Geophys., 8, 1, 11-20, 1990.

Kuichling, E.: The relation between the rainfall and the discharge of sewers in populous districts, Transactions ASCE, 20, 1, 1889.

Lloyd Davies, D. E.: The elimination of storm water from sewerage systems, Min. Proc. Inst. Civil Engineers, 164, 2, 41-67, 1906.

Matheron, G.: Les Variables Regionalizees et leur Estimation, (Local variations and their estimation) Masson, Paris, 1965.

Meyer, O. K.: Simplified flood routing Civil Engineering, New York, 11, 5, 306-307, 1941.
Minshall, N. E.: Predicting storm runoff from small experimental watersheds, J. Hydraul. Eng.-ASCE 86 (HY-8), 1960.

Mulvany, T. J.: On the use of self-registering rain and flood gauges in making observations of the relations of rainfall and of flood discharges in a catchment, Trans. Inst. Civ. Eng. Ireland, 4, II, $18-33,1851$.

McCarthy, G. T.: The unit hydrograph and flood routing, Unpublished paper presented at the Conference of the North Atlantic Division of U.S. Corps of Engineers, Providence, Rhode Island, June 1938, revised March 1939.

Napiorkowski, J. J.: Linear theory of open channel flow, in: Advances in Theoretical Hydrology, edited by: O'Kane, J. P., Elsevier, Amsterdam, 3-15, 1992.

Nash, J. E.: Determining runoff from rainfall, Proc. Institution of Civil Engineers, 10, 163-184, 1958.

O'Kelly, J. J.: The employment of unit-hydrographs to determine the flow of Irish arterial drainage channels, Inst. Civil Eng. (Ireland) Proc., 4, 365-412, 1955.

Pedlosky, J.: Geophysical Fluid Dynamics, Springer-Verlag, New York, 1979.

Philip, J. R.: The theory of infiltration, Soil Science, 83, 345-357, 435-448, 84, 163-178, 257-264, 1957.

Rodriguez-Iturbe, I. and Valdes, J. B.: The Geomorphologic structure of hydrologic response, Water Resour. Res., 15, 6, 14091420 (1250-1258), 1979.

Shamseldin, A. J. and Nash, J. E.: The Geomorphologic Unit Hydrograph - a Hydrology and Earth Systems Science Critical Review, 2, 1, 1-8, 1998 .

Shamseldin, A. J. and Nash, J. E.: Reply to Comment by G. G. S. Pegram, Hydrology and Earth Systems Sciences, 3, 2 , 311-314, 1999.

Turner, J. M. and Bourdoin, A. S.: The Flood hydrograph Boston Soc. Civ. Eng., 28, 3, 232-256, 1941.

Velikanov, M. A.: Oshibki Izmareniya I Empiricheskie Zavisimosti (Measurements Errors and Empirical Relations), GIMIZ, Leningrad, English transl, by Israel Programme for scientific translations, Jerusalem, 230 pp., 1962.

Wang, Q. J. and Dooge, J. C. I.: Limiting cases of land surface fluxes, XVI General Assembly of European Geophysical Society, Wiesbaden, April 1991, J. Hydrol., 155, 429-440, 1994.

Weinberg, G. M.: An Introduction to General Systems Thinking Wiley-Interscience, 1975.

Zoch, R. R.: On the relation between rainfall and streamflow, in: U.S. Dept. of Commerce, Monthly Weather Review, Part I, 62, 315-322, 1934.

Zoch, R. R.: On the relation between rainfall and streamflow, in: U.S. Dept. of Commerce, Monthly Weather Review, Part II, 64, 105-121, 1936.

Zoch, R. R.: On the relation between rainfall and streamflow, in: U.S. Dept. of Commerce, Monthly Weather Review, Part III, 65, 135-147, 1937. 